\title{
Simulink model of a Regenerative Shock Absorber
}

\author{
S. Vergura \\ Department of Electrical and information Engineering \\ Polytechnic University of Bari \\ st. E. Orabona, 4, 70125, Bari, ITALY \\ Phone:+0039080 5963590, e-mail: silvano.vergura@poliba.it
}

\begin{abstract}
The field of the Electric Vehicles (EVs) is becoming a strategic laboratory for new solutions focused on the energy saving and/or the renewable energy sources. Regenerative brakes are well known and already applied in recent cars. In this paper, instead, the attention is focused on a regenerative Shock Absorber (SA), which converts its vibration - induced by the road roughness - in electrical energy. The vibration is transmitted to an electric generator through a mechanical component. Finally, the produced energy can be stored in a super capacitor for a future use. The paper proposes a Simulink-based model of this regenerative SA and compares the energy performance when the vehicle travels roads with different roughness, scientifically defined by means an index, said IRI.
\end{abstract}

\section{Keywords}

Regenerative Shock absorber, IRI, Simulink, Model, Supercapacitor.

\section{Introduction}

The large amount of green-house gas emissions is caused from the extensive use of the fossil fuel worldwide. So, it needs to replace the fossil fuel energy with renewable clean energy to prevent the worsening of the environmental issues. Moreover, the reduction of the use of fossil fuel can lower the energy costs, even considering that, in USA, the automobiles are responsible of $70 \%$ of the carbon monoxide, $45 \%$ of the nitrogen oxide and $34 \%$ of the hydrocarbon pollution [1]. Vehicles consume over $40 \%$ of petroleum in USA and the exhaust causes more air pollution than anything else [2]. The relationship between the vehicle energy flow and the vehicle performance has been studied by researchers in [3], and it results that only about $14 \%-30 \%$ of the energy from the fuel is used to move it. Some results are comforting, considering that nowadays the braking energy recovery system is widespread in the automotive industry [4]. Moreover, as a consequence of the evolution toward smart grids, the vehicles are assuming a strategy value of the electrical grid, leading to opportunities to use the flexibility of the electric vehicles to optimize the peak demands for the electric distribution grids [5]. In a scenario with a high wind and photovoltaic penetration in the system, the electricity prices are determined by the instantaneous energy production. Wind turbines and PV systems are intermittent energy sources [6]-[7], whose production depends on the weather conditions; and this is a criticality for the stability and safety [8]. The criticalities regard the unpredictability of the produced energy and the efficiency of the plants that must be constantly monitored [9-13]. In this scenario, the energy exchange with the electric vehicles is stimulating the researchers in finding new solution, as the Vehicle-to-Grid (V2G) approach. Therefore, the role of the vehicle in supporting the reduction of carbon emissions and in making power systems more efficient is becoming increasingly important. The SA is the component of the vehicle suspension, combined with the suspension spring to filter vehicle vibration due to rough road. Energy from vibrational sources is usually dissipated as hydraulic friction and heat. Traditionally, several researchers have focused attention on the energy wasted in the SAs, examining the feasibility of harvesting energy from the $\mathrm{SA}$, as results in the literature [14-18]. In these papers, the approach was focused on the harvesting of the kinetic energy dissipated by the suspension. Successively, the studies on the regenerative SA have been concentrated on three different categories [19]: electromagnetic, hydraulic and mechanical designs. The first one is based on an electromagnetic method to generate the electric power, based on a linear electromagnetic regenerative SA that uses the electromagnetic induction to convert the kinetic energy of vertical oscillations into electricity [20]. The second category harvests the vibration energy and converts it into electricity, thanks to the oscillatory motion to drive a hydraulic motor, which is connected to a power generator [21]. The third one category is the mechanical regenerative SA, characterized by a greater efficiency than the previous technologies [22]. For this reason, this paper proposes the model of a Mechanical Regenerative SA (MRSA), implementing it in the Simulink environment. The paper is organized as follows. Section 2 introduces the electro-mechanical model, while Section 3 discusses the Simulink model and the simulation results. Conclusions end the paper.

\section{Model of the regenerative $\mathrm{SA}$ and preliminary results}

The MRSA under examination is described in [19] and is schematically represented in Figure 1, where $\mathrm{x}$ and $\mathrm{F}$ represent the position of the SA and the force due to the vibration, respectively. 
The main components of the MRSA are the two coaxial (inner and outer) cylinders, the transmission mechanism, the planetary gearbox, which actives an electric generator that, in turn, charges a supercapacitor.

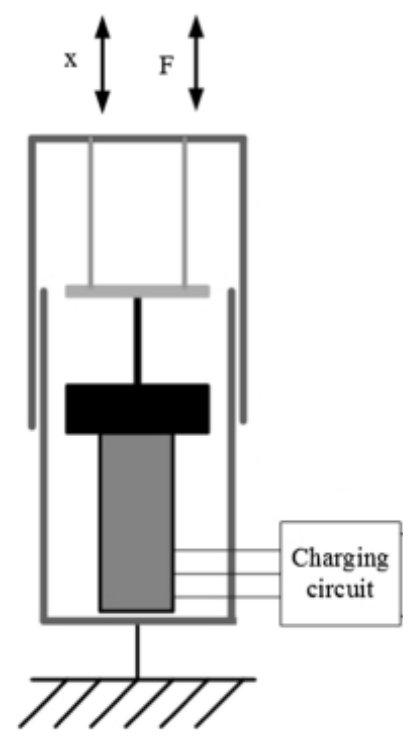

Figure 1. Simplified scheme of the MRSA.

An interesting consideration regards the electricity generation is that the MRSA produces energy for each relative movement between the inner cylinder and the outer cylinder, regardless of whether the movement is a compression or an extension. This happens because the structure of the transmission mechanism solicits the planetary gearbox always in the same direction.

The model will be based on the spring-damper system, considering the rigidity and the dumping of both the shock absorber and the tire, other than their mass. Figure 2 reports the principle scheme of the proposed regenerative $\mathrm{SA}$ (on the right) integrated in the standard quarter-car absorber (on the left) [1]. A quarter vehicle suspension system consists of the wheel assembly mass $\mathrm{m}_{1}$, the quarter vehicle mass $\mathrm{m}_{2}$, the tyre stiffness $\mathrm{k}_{1}$ and tyre damping $\mathrm{c}_{1}$, finally the suspension stiffness $\mathrm{k}_{2}$ and the suspension damping $\mathrm{c}_{2}$. The single speed regenerative $\mathrm{SA}$ is placed in between the quarter vehicle mass and wheel assembly mass and it provides the additional electromagnetic damping and generates the electrical energy. The variables $\mathrm{x}_{1}$ and $\mathrm{x}_{2}$ represent the displacement of the wheel assembly mass and the quarter vehicle mass, respectively; instead, $y$ is the road excitation displacement. The variable $\mathrm{B}$ is the magnetic field intensity, the product $\mathrm{Bl}$ is the electromechanical coupling constant, being 1 the total length of the coils; $U$ is the output voltage.

The electrical circuit is reported on the right of the Figure 2 , being $R_{i}$ the coil resistance and $L$ the coil inductance. The electrical power is extracted over the external resistor $\mathrm{R}_{\mathrm{e}}$.

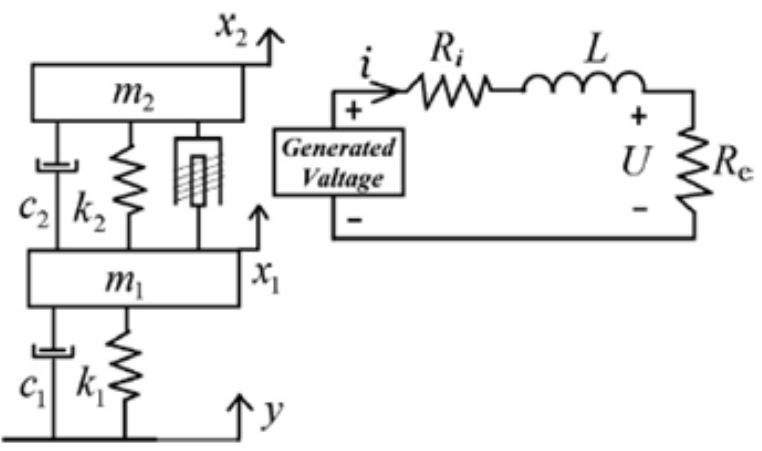

Figure 2. Quarter-car absorber and regenrative absorber.

The electro-mechanical system of Figure 2 is mathematically described by the following equations:

$$
\left\{\begin{array}{c}
\left(m_{1}+m_{m}\right) \cdot \ddot{x_{1}}+\left(c_{1}+c_{2}\right) \cdot \dot{x_{1}}-c_{2} \cdot \dot{x_{2}}+\left(k_{1}+k_{2}\right) \cdot x_{1}-k_{2} \cdot x_{2}-c_{1} \cdot \dot{y}-k_{1} \cdot y-\frac{B l U}{R_{e}}=0 \\
\left(m_{2}+m_{c}\right) \cdot \ddot{x_{2}}+c_{2} \cdot\left(\dot{x_{2}}-\dot{x_{1}}\right)+k_{2} \cdot\left(x_{2}-x_{1}\right)+\frac{B l U}{R_{e}}=0 \\
B l \cdot\left(\dot{x_{1}}-\dot{x_{2}}\right)-L \cdot \frac{\dot{U}}{R_{e}}-\frac{U}{R_{e}} \cdot\left(R_{i}+R_{e}\right)=0
\end{array}\right.
$$

\section{Simulink model and simulation results for three cases}

The values used for the system under test are reported in the Table 1 [1]. After the modelling, three different case studies will be considered, in order to compare the different amount of energy: highway, old pavement, rough road. These different roads are classified on the basis of the International Roughness Index (IRI), which defines the roughness level per $\mathrm{km}$ and the speed range. IRI is measured in $\mathrm{m} / \mathrm{km}$, i.e. the amount of asperities per $\mathrm{km}$ $[23,24]$. The IRI value, for each case under test, is reported in Table 2, whereas Figure 3 is the Simulink scheme of the regenerative SA of Figure 2. On the left-hand side, a twoways selector allows to load the characteristic parameter of the road tipology (highway, old pavment, rough road), the length of the path, the speed, and so on. The central part allows to extract the electrical variables of the regenerative SA (voltage and current).

Table 1. Parameters of the system in Figure 2.

\begin{tabular}{|l|c|l|}
\hline & Parameter & Value \\
\hline Wheel assemly mass & $\mathrm{m}_{1}$ & $40 \mathrm{~kg}$ \\
\hline Quarter veichle mass & $\mathrm{m}_{2}$ & $260 \mathrm{~kg}$ \\
\hline Tyre stiffness & $\mathrm{k}_{1}$ & $130.000 \mathrm{~N} / \mathrm{m}$ \\
\hline Supsension stiffness & $\mathrm{k}_{2}$ & $26.000 \mathrm{~N} / \mathrm{m}$ \\
\hline Tyre damping & $\mathrm{c}_{1}$ & $264.7 \mathrm{Ns} / \mathrm{m}$ \\
\hline Absorber damping & $\mathrm{c}_{2}$ & $520 \mathrm{Ns} / \mathrm{m}$ \\
\hline Electromagnetic coupling & $\mathrm{Bl}$ & $6.5 \mathrm{Tm}$ \\
\hline Coil resistance & $\mathrm{R}_{\mathrm{i}}$ & $113 \Omega$ \\
\hline Load resistance & $\mathrm{R}_{\mathrm{e}}$ & $113 \Omega$ \\
\hline Coil inductance & $\mathrm{L}$ & $94 \mu \Omega$ \\
\hline
\end{tabular}


Table 2. IRI (International Roughness Index) for different roads

\begin{tabular}{|l|c|l|}
\hline & Parameter & Value \\
\hline Highway & IRI & $2 \mathrm{~m} / \mathrm{km}$ \\
\hline Old pavement & IRI & $5 \mathrm{~m} / \mathrm{km}$ \\
\hline Rough road & IRI & $11 \mathrm{~m} / \mathrm{km}$ \\
\hline
\end{tabular}

Finally, the right-hand side allows to store the variables and to plot the time-series of voltage, current, power and energy. For each case under test, fixed the maximum value of the IRI, the roughness is randomly generated. Therefore, in order to evaluate the global effect during a long path, ten repetitions are considered and they cover a path of $10 \mathrm{~km}$. Figure 4 reports the time-serie of voltage, current, power and energy for the highway-case, i.e. for $I R I=2 \mathrm{~m} / \mathrm{km}$. The energy diagram is highlighted in blue color for a successive comparison with the other two cases.
Some statistics $(\mathrm{min} / \mathrm{max} / \mathrm{rms}$ value of voltage and currente, etc.) are reported in the first row of the Table 3. Figure 5, instead, reports the time-series of the electrical variables of the second case under test, the old pavement, having $I R I=5 \mathrm{~m} / \mathrm{km}$. The produced energy (blue box) has a linear behavior, as in the previous case, but the final value is higher than the previous case. The statistics are reported in the second row of Table 3.

Finally, Figure 6 diagrams the time-series of the electrical values of the third case, the rough road, having $I R I=11 \mathrm{~m} / \mathrm{km}$. The produced energy (blue box) is the highest one among the three investigated cases. The statiscs in the third row of Table 3 confirm that the rough road allows the maximum energy recovery.

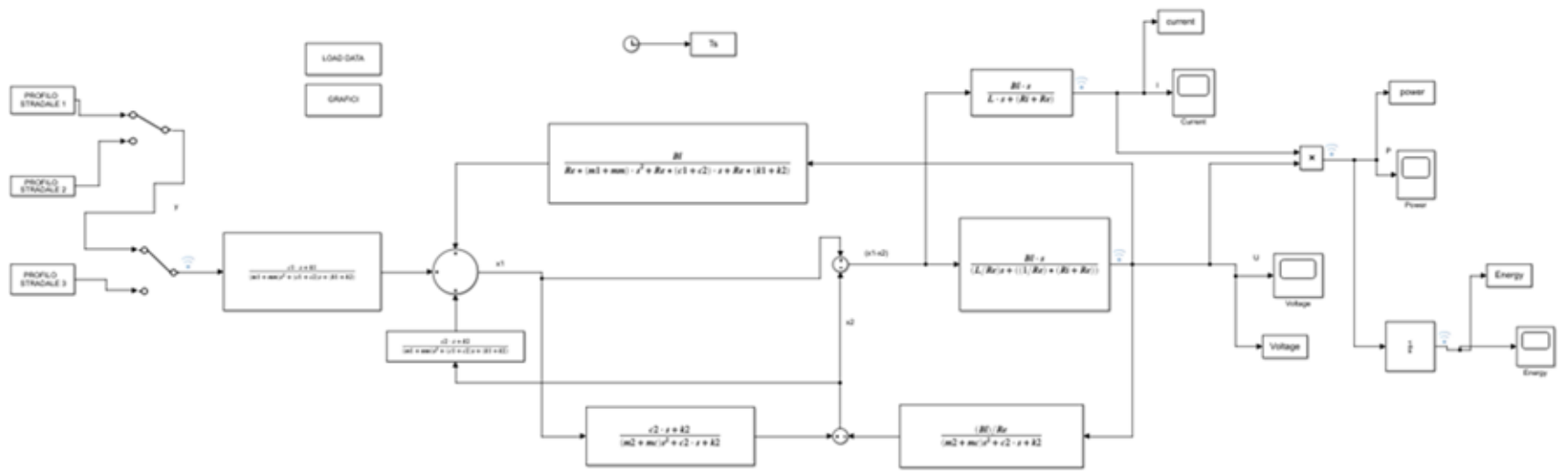

Figure 3. Simulink scheme of the regenerative SA to study three cases: highway, old pavement, rough road.
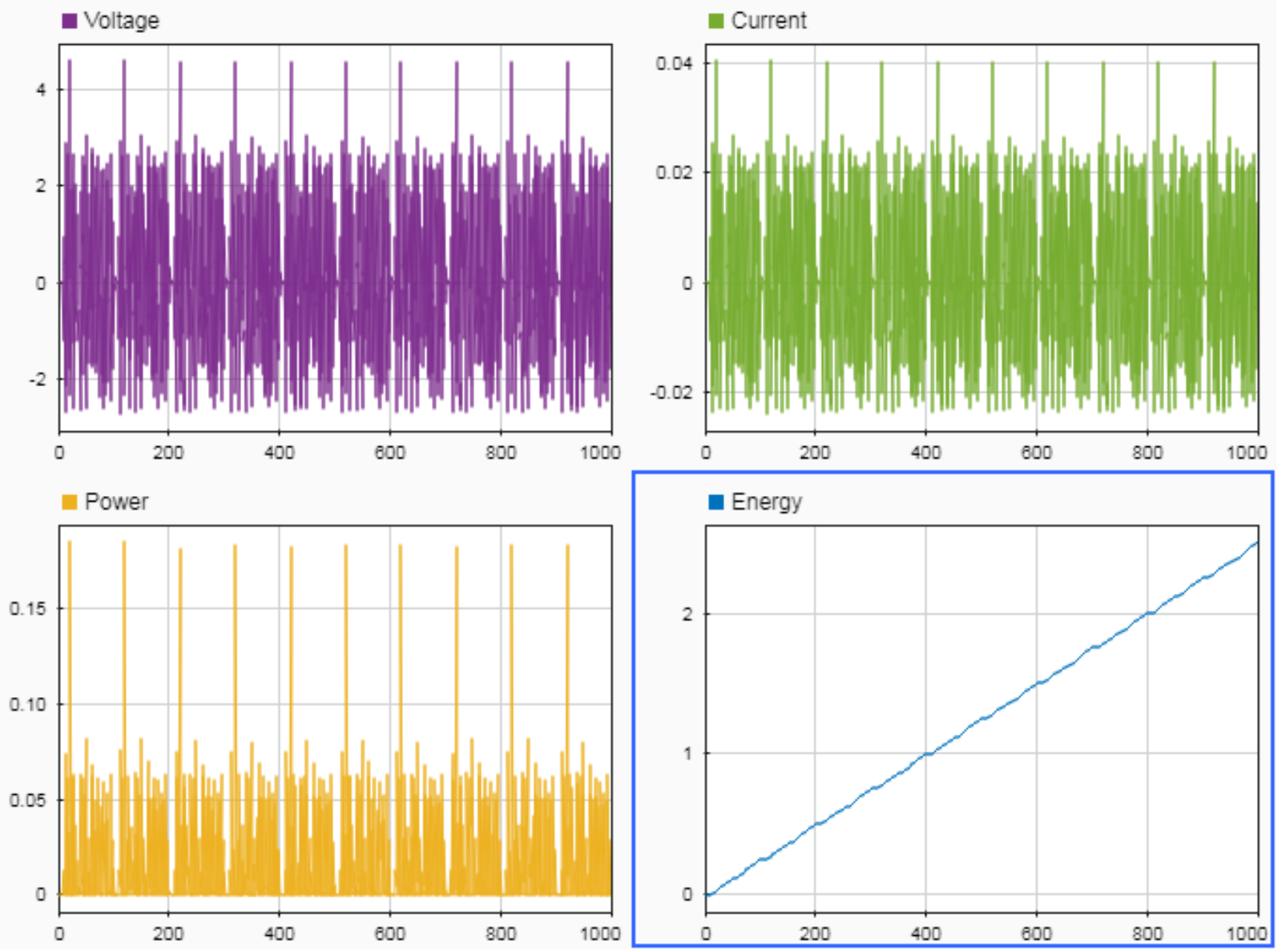

Figure 4. Voltage [V], Current [A], Power [W] and Energy [Ws] for the highway case. $(I R I=2 \mathrm{~m} / \mathrm{km})$. 

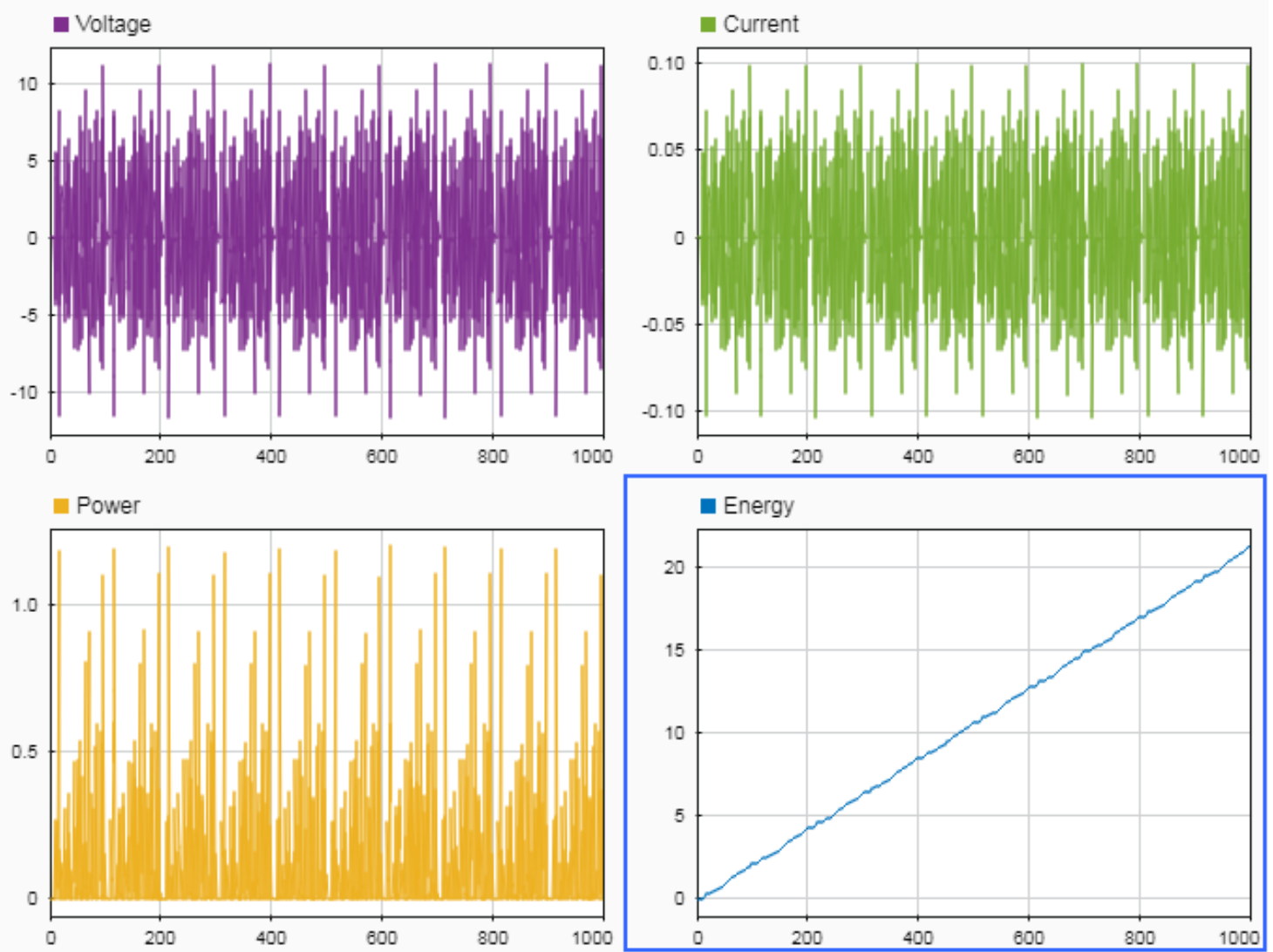

Figure 5. Voltage [V], Current [A], Power [W] and Energy [Ws] for the old pavement case $(I R I=5 \mathrm{~m} / \mathrm{km})$.
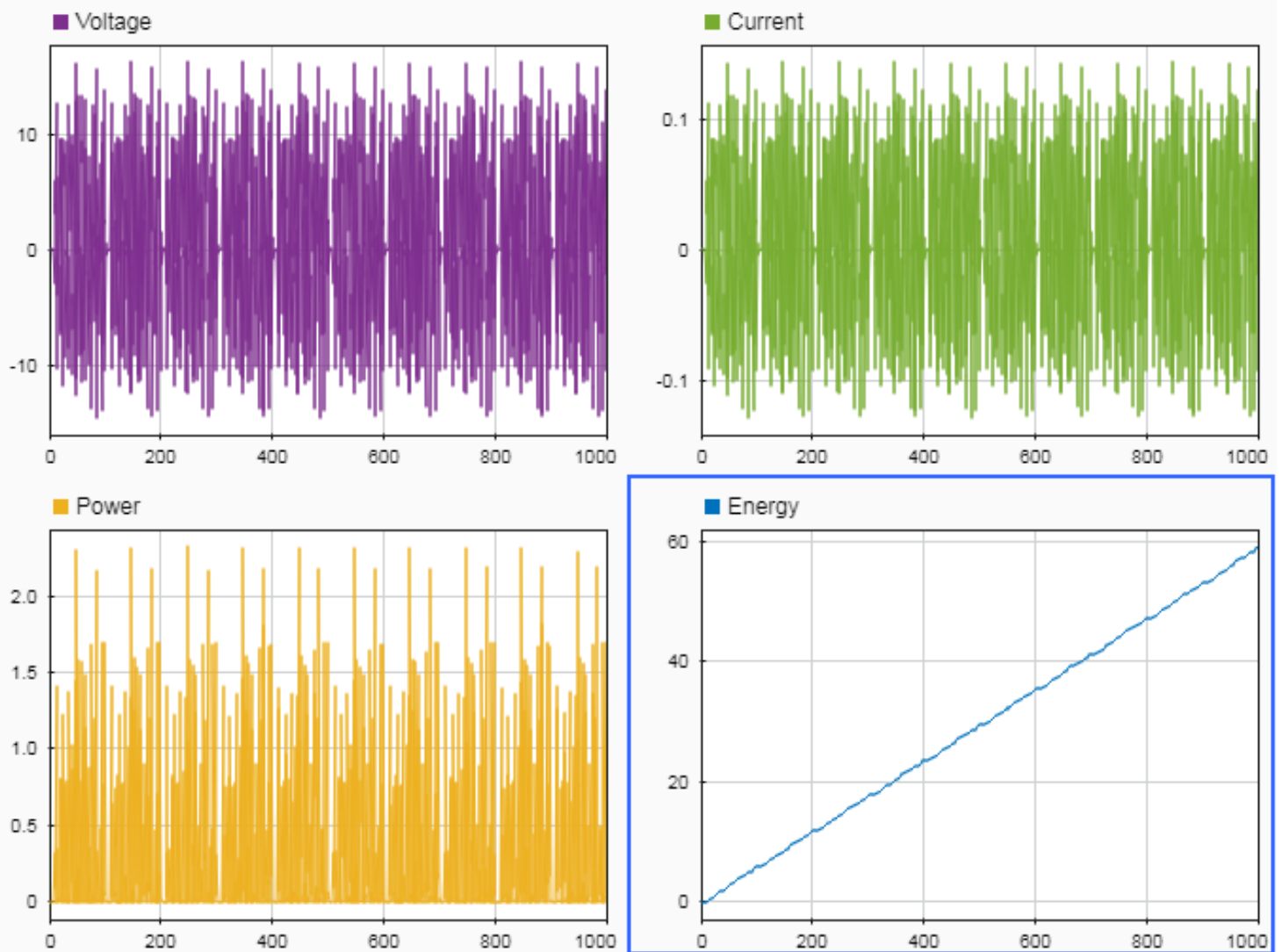

Figure 6. Voltage [V], Current [A], Power [W] and Energy [Ws] for the rough road case $(I R I=11 \mathrm{~m} / \mathrm{km})$. 
Table 3. Electrical parameters for the three cases under investigation.

\begin{tabular}{|c|c|c|c|c|c|c|c|c|}
\cline { 2 - 9 } \multicolumn{1}{c|}{} & \multicolumn{3}{c|}{ Voltage[V] } & \multicolumn{3}{c|}{ Current [A] } & Power [W] & Energy[Ws] \\
\cline { 2 - 9 } \multicolumn{1}{c|}{} & Max & Min & RMS & Max & Min & RMS & Mean value & Max \\
\hline Highway & 4.573 & $-2,705$ & 0.639 & 0.041 & -0.024 & 0.006 & 0.004 & 2.507 \\
\hline $\begin{array}{c}\text { Old } \\
\text { pavement }\end{array}$ & 11.193 & -11.646 & 1.921 & 0.099 & -0.103 & 0.017 & 0.032 & 21.247 \\
\hline Rough road & 16.189 & -14.456 & 3.208 & 0.143 & -0.128 & 0.028 & 0.091 & 59.100 \\
\hline
\end{tabular}

\section{Conclusions}

The paper discusses an electro-mechanical system that converts the vibrations, caused by the roughness of the road, into electrical energy, which, on its turn, supplies the electrical devices of the vehicle. The proposed system, implemented in Simulink environment, is based on the classification of the roads by means of the IRI, an index that measures the amount of roughness per $\mathrm{km}$. Three cases with very different values of IRI were studied: highway, old pavement and rough road. As expected, the latter one is the most efficient case, since the maximum energy is produced. It is important to note that other mechanical solutions are studied to gain the amount of the produced energy. Their aim is to double the inductive effect for a single vibration. From the electrical point of view, these systems are similar to the proposed one, but they have a gained electrical source. Thus, the proposed Simulink model can be re-used.

\section{References}

[1] R. Zhang, X. Wang, Z. Liu., "A novel regenerative shock absorber with a speed doubling mechanism and its Monte Carlo simulation", Journal of Sound and Vibration, Vol. 417, 2018, pp 260-276.

[2] Energy Information Administration Basic Petroleum Statistics, http://www.eia.doe.gov/basics/.

[3] US Department of Energy. Energy efficiency \& renewable energy. 2016. Where the Energy Goes: Gasoline Vehicles [DB/OL], http://www.fueleconomy.gov/feg/atv.shtml.

[4] C.T. Chung, Y.H. Hung, "Performance and energy management of a novel full hybrid electric powertrain system", Energy, 2015, vol.89:6, pp.26-36.

[5] E. Veldman, R. A. Verzijlbergh, "Distribution Grid Impacts of Smart Electric Vehicle Charging From Different Perspectives", IEEE Trans on Smart Grid, Vol. 6, Issue 1, January 2015, pp 333-342.

[6] S. Vergura, A. Massi Pavan, "On the photovoltaic explicit empirical model: Operations along the current-voltage curve", IEEE-ICCEP 2015, International Conference on Clean Electrical Power, Taormina, Italy, June 16-18, 2015, pp. 99-104.

[7] A. Massi Pavan, S. Vergura, A. Mellit, V. Lughi, Explicit empirical model for photovoltaic devices. Experimental validation, Solar Energy, Vol. 155, October 2017, pp. 647653.

[8] Eid C, Codani P, Perez Y, Reneses J, Hakvoort R. Managing electric flexibility from Distributed Energy Resources: a review of incentives for market design. Renewable Sustainable Energy Reviews, 2016;64:237-47.

[9] G. Acciani, O. Falcone, S. Vergura, "Analysis of the thermal heating of poly-Si and a-Si photovoltaic cell by means of Fem", Renewable Energy \& Power Quality Journal (2010), No.8.
[10] S. Vergura, F. Marino, "Quantitative and Computer Aided Thermography-based Diagnostics for PV Devices: Part I - Framework", IEEE Journal of Photovoltaics, Vol. 7, Issue 3, May 2017, pp 822-827.

[11] S. Vergura, M. Colaprico, M. F. de Ruvo, F. Marino, “A Quantitative and Computer Aided Thermography-based Diagnostics for PV Devices: Part II - Platform and Results", IEEE Journal of Photovoltaics, Vol. 7, Issue 1, January 2017, pp 237-243.

[12] S. Vergura, F. Marino, M. Carpentieri, "Processing infrared image of PV modules for defects classification", ICRERA 2015, International Conference on Renewable Energy Research and Applications, Palermo, Italy, 2015.

[13] S. Vergura, E. Natangelo, "Labview-matlab integration for analyzing energy data of PV plants", RE\&PQJ (ISSN 2172-038X), Renewable Energy \& Power Quality Journal, No.8, 635, April 2010.

[14] L. Segel, L.X. Pei, "Vehicular resistance to motion as influenced by road roughness and highway alignment", Aust Road Res, 1982, 12(4), pp. 211-222.

[15] D. Karnopp, "Permanent magnet linear motors used as variable mechanical dampers for vehicle suspensions", Veh Syst Dyn, 1989, 18, pp 187-200.

[16] A. Abouelnour, N. Hammad, "Electric utilization of vehicle damper dissipated energy", Al-azhar engineering seventh international conference (AEIC), Cairo, Egypt, April 7-10, 2003.

[17] L. Zuo, P. Zhang, "Energy harvesting, ride comfort, and road handling of regenerative vehicle suspensions", J Vib Acoust, 2013, vol. 135.

[18] B. Huang, C. Hsieh et al., "Development and optimization of an energy regenerative suspension system under stochastic road excitation", J. Vib Acoust, 2015, vol. 357, pp 16-34.

[19] Z. Zhang, X. Zhang, W. Chen, Y. Rasim, W. Salman, H. Pan, Y. Yuan, C. Wang, "A high-efficiency energy regenerative shock absorber using supercapacitors for renewable energy applications in range extended electric vehicle", Applied Energy, Vol. 178, 2016, pp. 177-188.

[20] N. Satute, S. Singh, S.M. Sawant, "Energy harvesting shock absorber with electromagnetic and fluid damping", Adv Mech Eng, 2014.

[21] C. Li, R. Zhu et al., "Study on a novel hydraulic pumping regenerative suspension for vehicles", J Vib Acoust, 2014, vol. 333, pp 3904-3916.

[22] Z. Li, L. Zuo et al., "Energy-harvesting shock absorber with a mechanical motion rectifier", Smart Mater Struct, 2013, vol. 22, 025008.

[23] M. Sayers, T. Gillespie, C. Queiroz, "The International Road Roughness Experiment”, World Bank, Washington DC, Technical Paper, 1986, No. 45.

[24] P.R. Pawara, A.T. Mathewb, M.R. Saraf "IRI (International Roughness Index): An Indicator Of Vehicle Response“, ICMMM - Materials today: proceedings, 2017, 5(5), pp 11738-11750. 